\title{
Description of the laRvae of CRicotopus Festivellus (KiefFer 1906) AND CRICOTOPUS DIVERSUS (BOESEL 1983) WITH KEYS TO DISCRIMINATION OF larval, PUPal and adult STAGes (Diptera: Chironomidae)
}

\author{
Hub Cuppen ${ }^{1}$, Susan E. Gresens ${ }^{2,3}$ and David Tempelman ${ }^{4}$ \\ ${ }^{1}$ Adviesbureau Cuppen, Hogeweg 8, 6961 LT Eerbeek, The Netherlands, E-mail: hpjj.cuppen@gmail.com \\ ${ }^{2}$ Dept. of Biological Sciences, Towson University, 8000 York Road, Towson, MD 21252, USA \\ ${ }^{3}$ Dept. of Natural History, NTNU University Museum, Norwegian University of Science and Technology, \\ NO-7491,Trondheim,E-mail: sgresens@towson.edu, corresponding author \\ ${ }^{4}$ Tempelman Ecologie, Soembawastraat 25F, 1095 VV Amsterdam, The Netherlands, \\ E-mail:_davidtempelman67@gmail.com
}

\begin{abstract}
The larva of two very similar Cricotopus species are described for the first time: Cricotopus diversus (Nearctic) and C. festivellus, new description (West Palaearctic). Confusion can arise depending on the source used for identification of Nearctic Cricotopus. The key of LeSage and Harrison (1980) treated adults and exuviae of $C$. diversus as variants of $C$. festivellus. Subsequently Boesel (1983) formally described C. diversus and included it in keys to adult Cricotopus of the eastern United States. Adults of these species have been distinguished by consistent differences in the pigmentation on the fourth and fifth abdominal tergites; we also confirmed differences in the structure of the male hypopygium. Keys to larvae, pupal exuviae and adult males are presented. Publicly available DNA barcode records document $C$. diversus populations in the Mid-Atlantic US and Ontario, Canada, whereas barcode records of $C$. festivellus were available only for Scandinavia, although this species is widely distributed in Western Europe. These two species are genetically distinct, with $13 \%$ mean difference in barcode sequence between species. Both species are reported from rivers and lakes of relatively good water quality.
\end{abstract}

\section{Introduction}

The genus Cricotopus van der Wulp 1874 is large, with 218 species distributed widely across most biogeographic regions. It is not surprising given this level of diversity that Cricotopus species differ in microhabitat preference and their tolerance to pollution (Haase and Nolte 2008; Moller Pillot 2013, Krosch et al. 2015). Cricotopus larvae can be difficult to identify to species, and some are even difficult to distinguish from Orthocladius larvae without associated rearing of pupae or adults (Epler 2001, Cuppen and Tempelman 2018). Hirvenoja (1973) revised the genus for the western Palaearctic, but similar treatment of Nearctic Cricotopus is lacking and additional species await description (Epler 2001). The status of some closely related pairs of Nearctic and Palaearctic Cricotopus species have been subject to debate (Sublette 1964, Oliver 1977, Boesel 1983, Gresens et al. 2012). LeSage and Harrison (1980a) described "C. festivellus" from Southern Ontario but noted discrepancies in pigmentation pattern compared with the diagnosis in Hirvenoja (1973). Subsequently, Boesel (1983) considered this variation in his decision to describe $C$. diversus as a distinct Nearctic species, distributed from Michigan and Ohio (including western Lake Erie) to New York and Delaware. The descriptions in LeSage and Harrison (1980a) match those of our adult and pupal $C$. diversus, and we suspect that these were the same species.

Such taxonomic ambiguity complicates bioassessment of water quality, although application of DNA sequence data (i.e., "DNA barcoding") promises to facilitate identification of chironomid larvae (Ekrem et al. 2007, Failla et al. 2016) by referring to a "barcode library" of sequence data from adults and pupae which have been identified based on morphological criteria. Nevertheless, larvae of some species still remain to be associated with their adult and pupal life stages. Here we describe the larval stages of two very similar $\mathrm{Cri}$ cotopus species: Holarctic C. festivellus (Kieffer) and the Nearctic endemic $C$. diversus (Boesel) and use DNA barcoding data to compare the genetic distance between these species.

Neither Hirvenoja (1973), LeSage and Harrison (1980a) nor Boesel (1983) described the larval stage. The ability to identify chironomid larvae is needed to connect their tolerance to environmental stressors. In western Europe tolerance values for C. festivellus remain unclear because these larvae may have been confused with species of the cylindraceus group, as well as with other members of the festivellus species group: C. albiforceps and $C$. flavocinctus (Moller Pillot 2013). Similarly, there 
has been confusion over species' ranges in the Nearctic: LeSage and Harrison (1980a) included C. festivellus in their descriptions of Cricotopus species from a stream in Ontario, Canada, however their work pre-dated Boesel's (1983) description of $C$. diversus from Lake Erie. Although both authors noted subtle differences in color pattern in the adult form of the Nearctic species compared to Palaearctic C. festivellus, both species are listed as occurring in the Nearctic (Ashe and O'Connor 2012).

\section{Materials and Methods}

Cricotopus festivellus material was collected in the Netherlands and Norway. In the Netherlands, material originated from a non-natural stream, a moorland pool, a lake and a ditch with seepage. Norwegian specimens were collected from lakes and a pond near Trondheim (details in Table 1), and now reside in the collection of the Norwegian University of Science and Technology (NTNU) University Museum, Trondheim. Cricotopus diversus larvae were collected from Baismans Run, a small second-order stream in a forested catchment within Oregon Ridge Park, Baltimore County, Maryland (MD), USA (Fig. 1A, Table 1).

Larvae of $C$. diversus were gently removed from rocks bearing attached algae and water moss, and reared in individual aerated jars at 12:12 (L:D) photoperiod and temperature regime of $18^{\circ} \mathrm{C}: 15^{\circ} \mathrm{C}$
(D:N). Larvae were fed with epilithic algae from Baismans Run (Table 1) and water changes were conducted weekly. Jars were inspected daily for emerged adults and associated pupal exuviae. Two legs from each adult were used to obtain COI nucleotide sequence data from the Canadian Centre for DNA Barcoding, following their standard procedures (Ratnasingham and Hebert 2007). These barcode data are available from the Barcode of Life Datasystems (www.boldsystems.org). Specimens were prepared by clearing adults with proteinase $\mathrm{K}$; the adult exoskeleton was dissected and slidemounted in Euparal with the associated pupal and larval exuviae. Use of morphological terminology follows Sæther (1980).

Molecular genetic data provides an independent line of evidence which complements morphological discrimination of species. Sequence data for the cytochrome oxidase (COI) gene, i.e., "DNA barcodes" were previously obtained for larval $C$. diversus and the Norwegian $C$. festivellus specimens by the Canadian Centre for DNA Barcoding and are publicly available from BOLD, the Barcode of Life Datasystem v4 (www.boldsystems. org; Ratnasingham and Hebert 2007). As part of its goal to expedite the use of barcodes in description and enumeration of species diversity, BOLD maintains a Barcode Index Number (BIN) System, in which an clustering algorithm is used to cluster specimens with similar barcodes (starting

Table 1. Location details of studied material. $\mathrm{LA}=4^{\text {th }}$ instar larva; $\mathrm{PU}=$ pupa; $\mathrm{PEX}=$ pupal exuviae. $\mathrm{HC}=$ Hub Cuppen, RW = Rink Wiggers, $\mathrm{SG}=$ Susan Gresens, TE $=$ Torbjørn Ekrem

\begin{tabular}{|c|c|c|c|c|c|c|c|c|c|c|}
\hline Species & Stage & $\#$ & Location & Nearest town & Country & Water type & Lat. & Long. & Coll. date & Leg. \\
\hline $\begin{array}{l}\text { Cricotopus } \\
\text { diversus }\end{array}$ & LA, PU & 5,7 & Baismans Run & $\begin{array}{l}\text { Cockeysville, } \\
\text { MD }\end{array}$ & USA & $\begin{array}{l}\text { small forest } \\
\text { stream }\end{array}$ & 39.4795 & -76.6917 & 11-Sep-10 & SG \\
\hline $\begin{array}{l}\text { Cricotopus } \\
\text { diversus }\end{array}$ & PEX & 6 & Chimney Branch & $\begin{array}{l}\text { Reisterstown, } \\
\text { MD }\end{array}$ & USA & $\begin{array}{l}\text { small forest } \\
\text { stream }\end{array}$ & 39.4062 & -76.8589 & 1-Jul-02 & SG \\
\hline $\begin{array}{l}\text { Cricotopus } \\
\text { festivellus }\end{array}$ & LA, PU & 1,1 & Grift & Apeldoorn & NL & $\begin{array}{l}\text { unnatural } \\
\text { stream }\end{array}$ & 52.2117 & 5.9651 & 30-Mar-05 & $\mathrm{HC}$ \\
\hline $\begin{array}{l}\text { Cricotopus } \\
\text { festivellus }\end{array}$ & LA & 1 & Landweerven & Enschede & NL & $\begin{array}{l}\text { moorland } \\
\text { pool }\end{array}$ & 52.2367 & 6.9347 & 18-May-09 & $\mathrm{HC}$ \\
\hline $\begin{array}{l}\text { Cricotopus } \\
\text { festivellus }\end{array}$ & LA & 1 & Veluwerandmeer & Biddinghuizen & NL & lake & 52.4154 & 5.7179 & 6-Oct-16 & RW \\
\hline $\begin{array}{l}\text { Cricotopus } \\
\text { festivellus }\end{array}$ & PEX & 1 & Den Dulvert & Waspik & NL & $\begin{array}{l}\text { ditch with } \\
\text { seepage }\end{array}$ & 51.6880 & 4.9736 & 4-Aug-92 & $\mathrm{HC}$ \\
\hline $\begin{array}{l}\text { Cricotopus } \\
\text { festivellus }\end{array}$ & $\begin{array}{l}\text { Adult } \widehat{\varnothing} \\
\text { NO73 }\end{array}$ & 1 & Lake Målsjøen & $\begin{array}{l}\text { Klæbu, } \\
\text { Trøndelag }\end{array}$ & NO & lake & 63.2460 & 10.4374 & 30-May-11 & $\begin{array}{l}\mathrm{SG}, \\
\mathrm{TE}\end{array}$ \\
\hline $\begin{array}{l}\text { Cricotopus } \\
\text { festivellus }\end{array}$ & $\begin{array}{l}\text { Adult } \widehat{\partial} \\
\text { NO60 }\end{array}$ & 1 & Lake Målsjøen & $\begin{array}{l}\text { Klæbu, } \\
\text { Trøndelag }\end{array}$ & $\mathrm{NO}$ & lake & 63.2460 & 10.4374 & 30-May-11 & $\begin{array}{l}\mathrm{SG}, \\
\mathrm{TE}\end{array}$ \\
\hline $\begin{array}{l}\text { Cricotopus } \\
\text { festivellus }\end{array}$ & $\begin{array}{l}\text { Adult }+ \\
\text { NO63 }\end{array}$ & 1 & $\begin{array}{l}\text { Bymarka, } \\
\text { Blomstertjønna }\end{array}$ & $\begin{array}{l}\text { Trondheim, } \\
\text { Trøndelag }\end{array}$ & $\mathrm{NO}$ & upland lake & 63.4193 & 10.2614 & 31-Jul-11 & SG \\
\hline $\begin{array}{l}\text { Cricotopus } \\
\text { festivellus }\end{array}$ & $\begin{array}{l}\text { Adult } \precsim \\
\text { NO56 }\end{array}$ & 1 & $\begin{array}{l}\text { Ringve botaniske } \\
\text { hage }\end{array}$ & $\begin{array}{l}\text { Trondheim, } \\
\text { Trøndelag }\end{array}$ & NO & pond & 63.4489 & 10.4532 & 24-Jul-11 & SG \\
\hline
\end{tabular}


at about $2 \%$ sequence variation) into operational taxonomic units, each identified by a unique code, its BIN. A test of the correspondence of BINs with traditionally defined species in large datasets of well-studied taxa was very high, finding that $89 \%$ of BINs corresponded exactly with described species (Ratnasingham and Hebert 2013). In order to compare the genetic diversity within and between species, we accessed the "Public Data Portal BIN Page" on BOLD for BOLD:AAP5924 (C. diversus) and BOLD:AAV1707 (C. festivellus). A BIN page includes a record list of all specimens in that BIN which are registered on BOLD, with information on their taxonomy, collection location and depository, and links for download of sequence data. The BIN for C. festivellus is based on specimens in the collections of the Swedish Museum of Natural History and the NTNU University Museum.

The MEGA7 package (Kumar et al. 2016) was used to compare genetic distances within and between species. FASTA files containing the COI sequences for each BIN were downloaded from BOLD. Alignment of the combined sequences by nucleotide was carried out in MUSCLE; mean genetic distances within species and between $C$. diversus and $C$. festivellus were subsequently calculated.

\section{Taxonomy}

\section{Cricotopus festivellus Kieffer, 1906:18}

Cricotopus (Cricotopus) festivellus (Kieffer), Hirvenoja, 1973:225

Description of larval $C$. festivellus: based on $4^{\text {th }}$ instar larvae $(n=3)$. Measurements of bilaterally symmetric structures are reported as mean values per specimen. Head capsule width 334-344 $\mu \mathrm{m}$ (n $=2)$.

Head capsule yellow, sometimes proximal part light brown. Postoccipital margin dark brown. Bifid S1 setae with branches of similar size; S2 seta simple (Fig. 2A). Antennae 5 segmented, Lauterborn organs well-developed and extending $2 / 3$ $-3 / 4$ the length of antennal segment 3 . Total antennal length $85-90 \mu \mathrm{m}$. Antennal blade extends to last segment, accessory blade half that length. Antennal ratio 1.9-2.1, mean $2.0(\mathrm{n}=3)$. Pecten epipharyngis composed of 3 scales. Mandible and 3 inner teeth, brown extending to molar area with wide pale base (Fig. 2A), length $136 \mu \mathrm{m}$. Outer margin of mandible smooth. Seta subdentalis yellow, ca. 2 times long as wide with a notched asymmetric tip which reaches the last free mandible tooth. Seta interna with 6 branches. Premandibula simple. Galea of maxilla with two or three rows of pectinate lamellae.

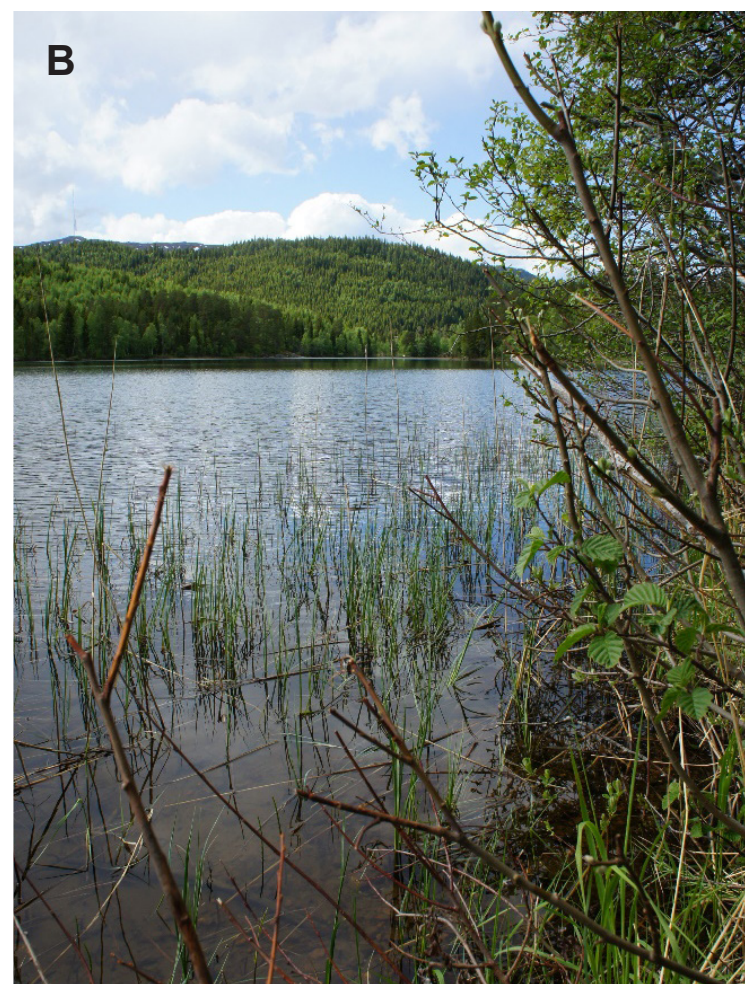

Figure 1. A) Baismans Run (USA) where larvae of Cricotopus diversus were collected. B) Lake Målsjøen (Norway) where larvae of Cricotopus festivellus were collected. 

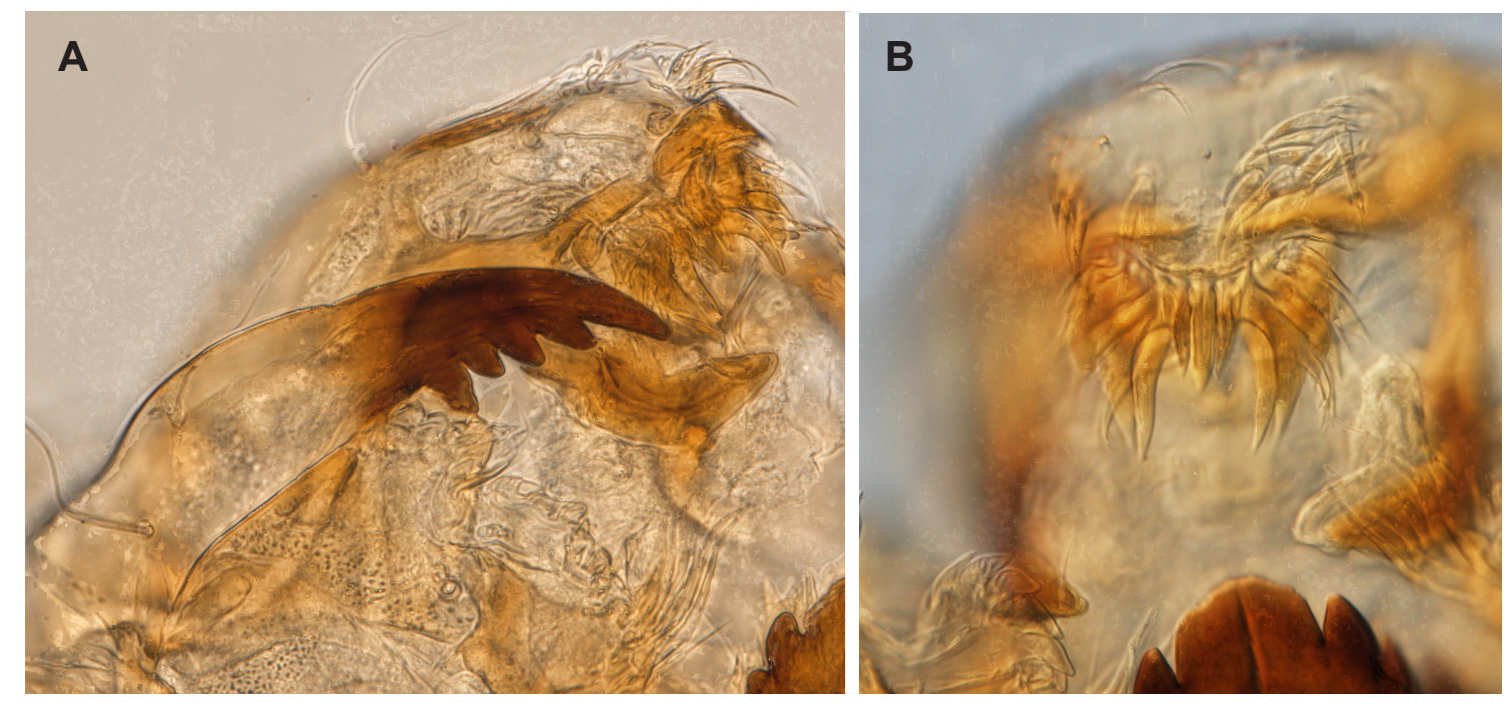

Figure 2. A) Cricotopus festivellus; mandible and premandible. Enschede, Landweerven, 18 May 2009. B) Cricotopus festivellus; epipharynx and S1. Veluwerandmeer, 5 October 2016.

Mentum with 6 brown lateral teeth; median tooth projecting forward and at most 3 times wider than first lateral tooth; MR (width of median tooth/ width first lateral tooth ranges from 2.7-3.0, mean $2.85(\mathrm{n}=3)$. VM-plate reaches $1^{\text {st }}$ lateral tooth. Submental setae located at the level of the fourth lateral tooth of the mentum.

Middle-sized claws of the anterior parapods with inner teeth at most half as long as apical tooth (Fig. 6B). Abdominal segments 1 - 6 bear posterolateral setal tufts of 12-24 filaments. Length of tufts from $70-240 \mu \mathrm{m}$, reaching up to half to $3 / 4$ the length of the segment. Setal tufts on segment VII bear 8-10 setae which are shorter than the setae on I - VI. (Fig. 3).

Procercus wider than long, bearing a sclerotized scale and 5-6 apical setae plus 2 fine lateral setae. Supra-anal setae $78-83 \mu \mathrm{m}$, as long or slightly longer as the anal tubules.

Pupa: The pupa of Cricotopus festivellus is described by Hirvenoja (1973) and Langton (1991). Exuviae light brown, characterized by frontal setae located on prefrons, 4 lateral setae on segment VIII with L4 not larger than the other lateral setae. Thoracic horn distally pointed and covered with small spinules. Pedes spurii B obvious on segment II but absent or weak on III. Tergite II usually with an extensive area of small spinules, variable, but at always at least bearing a transverse band of spinules anterior to the hooklet row. Tergites III-VI with median and posterior transverse bands of small points separated, but usually joined laterally, leaving a conspicuous median bare patch in the region of the posterior muscle marks.

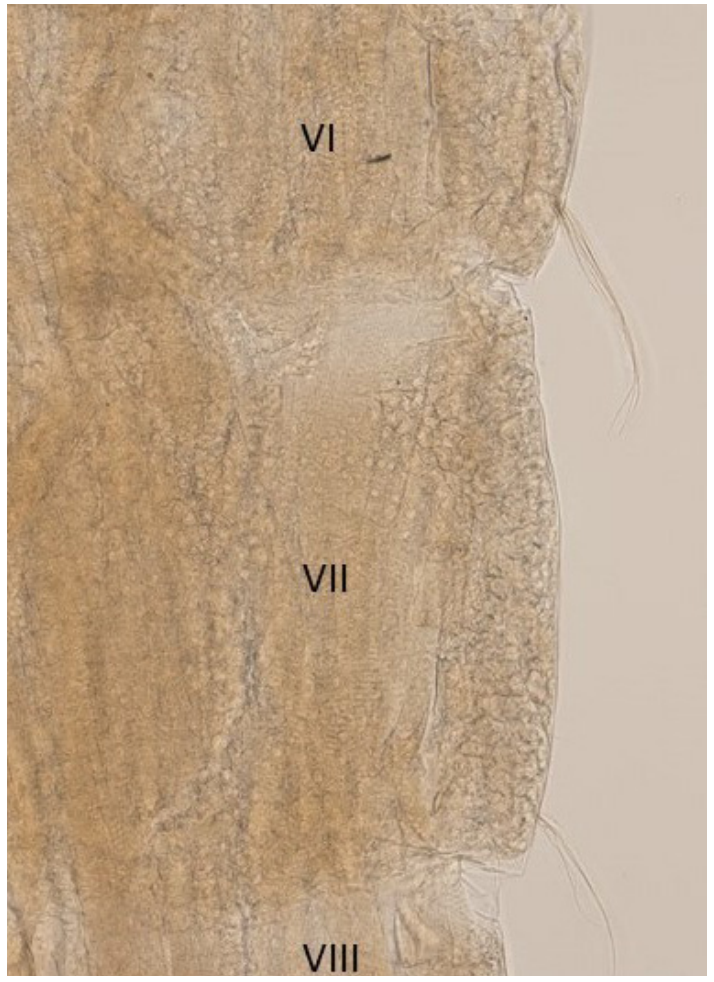

Figure 3. Cricotopus festivellus; lateral tufts on segment 6 and 7. Veluwerandmeer, 5 October 2016.

Specimens examined: NTNU University $\mathrm{Mu}-$ seum: 200820 (NO56), 200824 (NO60), 200826 (NO63), 200831 (NO73); H. Cuppen personal collection: 3 larvae, one with associated pex, 1 pex (Table 1).

DNA barcodes (BOLD Process IDs): BSCHI522-17, BSCHI708-17, BSCHI731-17, CHRFI512-11, CHRFI729-11, CHRSV514-11, CHRSV515-11, CHRSV517-11 = NO56, CHRSV521-11 = NO60, CHRSV524-11 = NO63, NEACH003-12 = NO73. 


\section{Cricotopus diversus Boesel, 1983:85.}

nec LeSage and Harrison 1980:94, C. (s.s.) festivellus

Description of larval $C$. diversus: based on $4^{\text {th }}$ instar larval exuviae $(n=5)$ with total length 3.5-4 $\mathrm{mm}$. Measurements of bilaterally symmetric structures are reported as mean values from both sides of specimen. Head capsule light golden, head capsule width $=369 \mu \mathrm{m}(\mathrm{n}=4)$. Bifid S1 setae with branches of similar size; S2 seta simple. Antennae 5 segmented, Lauterborn organs well-developed and extending $2 / 3$ the length of antennal segment 3. Antennal blade extends to last segment, accessory blade half that length. Antennal ratio (AR = basal segment/distal segments) 1.3-1.6, mean $1.41(\mathrm{n}=4)$. Pecten epipharyngis composed of 3 subequal scales. Mandible with 3 inner teeth, color brown extending to molar area with wide pale base. Outer margin of mandible smooth. Seta subdentalis grey, ca. 2 times long as wide with a notched asymmetric tip with one half blunt and the other half produced to a sharp point. Seta interna with 6 branches. Premandible simple. Galea of maxilla with no more than 2 rows of pectinate lamellae along the base of the scale-like marginal lamellae. Mentum with 6 brown lateral teeth; median tooth strongly projecting forward and at least 3 times wider than first lateral tooth MR (width of median tooth/width first lateral tooth ranges from 3.0- 3.8, mean $3.53(n=5)$. The median tooth, first and second lateral teeth are slightly grey compared to the brown lateral teeth. VM-plate reaches only 2nd lateral tooth. Submental setae located at the level of the basal corners of the mentum.

Large claws of the anterior parapods with robust inner teeth at least three quarters as long as apical tooth (Fig. 6A). Abdominal segments $1-6$ bear posterolateral setal tufts of 10-26 filaments. Length of tufts from $108-200 \mu \mathrm{m}$, up to half the length of a segment. Setal tufts on segments I and VI bear fewer and shorter setae. Procercus wider than long, bearing a sclerotized scale and 5-6 apical setae plus 2 fine lateral setae.

Pupal exuviae of $C$. diversus: Measurements are mean values $(n=10)$ unless stated otherwise. Length 3.5-4 mm, general color yellowish, tergites darker, sternites colorless. Frontal warts absent. Frontal setae fine, located on prefrons, $64 \mu \mathrm{m}$. Thoracic horn (TH, Fig. 4) length $106 \mu \mathrm{m}, \mathrm{L} / \mathrm{W}$ 9.9. Two median antepronotal setae: 153 and 130 $\mu \mathrm{m}$ long. Three precorneal setae: 160, 143, 124 $\mu \mathrm{m}$, distinctly longer than TH. Notum weakly granular along eclosion line.

Abdomen with Pedes spurii B on segment II, but absent on segment III. Pedes spurii A on sternites 4-6. Hooklet row on tergite 2 with 37-58 hooklets, mean $=47$; hooklet row covers 0.42 of width of segment $(580 \mu \mathrm{m})$. Armament of abdominal tergites (T) as follows: TI bare, TII may bear a very small number of fine points immediately anterior to hooklet row, or points absent. TIII with 2 patches of strong spinules: distinct median and posteromedian patches may merge around a central oval clear area. TIV and TV similar: more extensive median and posteromedian spinule patches are clearly merged, or with small median clear oval (Fig. 8A). TVI spinule patch less extensive; may appear as 2 distinct patches. TVII and TVIII similar: 2 anterolateral patches of fine spinules, less extensive on TVIII. Lateral setae distributed as

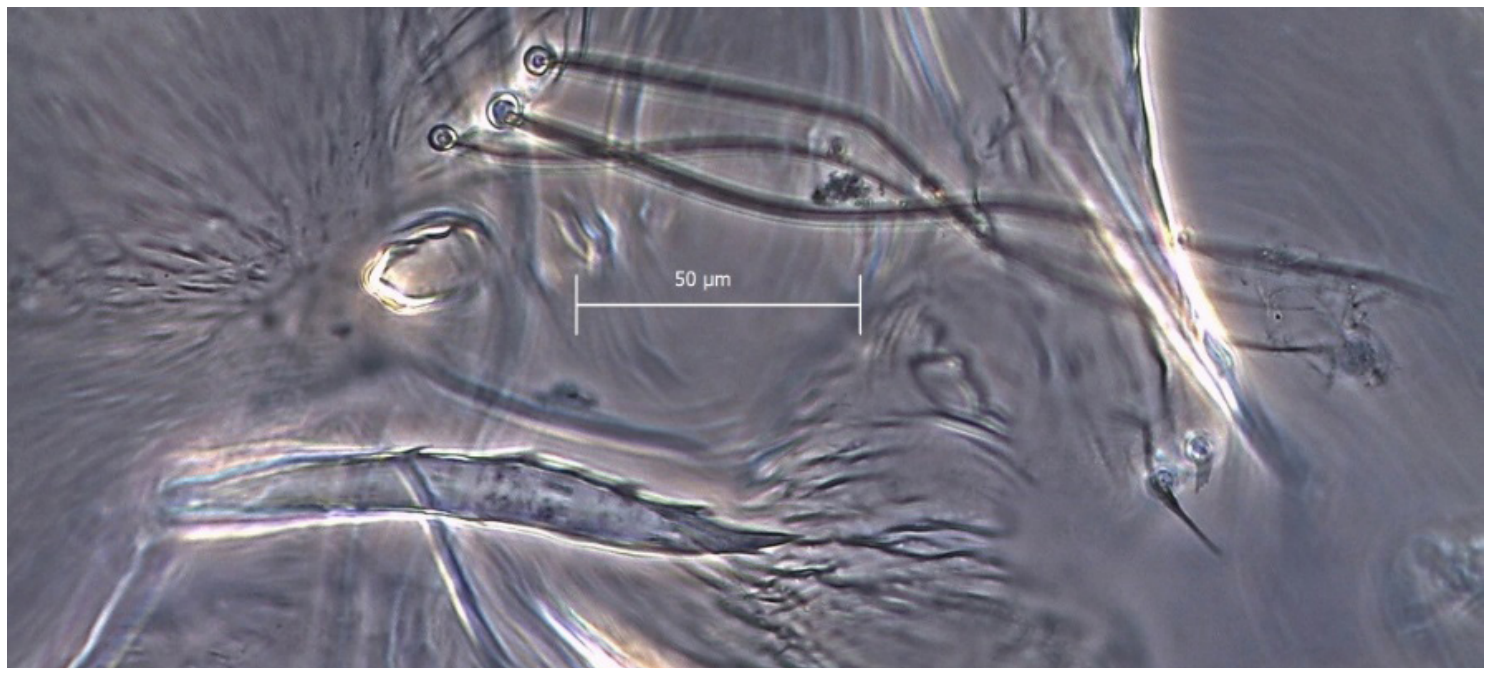

Figure 4. Cricotopus diversus; respiratory organ and precorneal setae (400x). Oregon Ridge Park, Baismans Run, 11 September 2010. 
follows: one seta on segment 1 and 3 on segments 2-7. Segment 8 bears 4 L setae, with L4 no larger than L3. Sternites SI and SII without fine spinules. SIII and SIV with very fine spinules primarily on lateral areas of sternite. SV and SVI with 2 anterolateral patches of fine spinules and a posteromedian patch. SVII with 2 anterolateral patches of small spinules whereas SVIII bears fine spinules only in lateral areas. Anal lobe slightly wider than long: mean length $199 \mu \mathrm{m}$, width $223(\mathrm{n}=7)$. The three anal lobe macrosetae of equivalent length, $172 \mu \mathrm{m}(\mathrm{n}=11)$.

Re-description of adult $\boldsymbol{C}$. diversus, based on holotype, paratypes and MD specimens:

Male: Head and antennae brown, Antennal ratio (AR) 1.4 (Boesel 1983) to $1.49(\mathrm{MD}, \mathrm{n}=3)$. Thorax brown with lighter humeri; vittae, and notum darker brown to black. Scutellum dark brown with an irregular row of fine bristles. Leg ratio (foretarsal segment 1 /fore-tibia) $=0.62($ Boesel 1983), $\mathrm{LR}=0.61$ (MD). Foreleg brown, except for tibia: basal $15 \%$ brown, medial white ring and distal $30 \%$ brown. Mid and hind legs with brown femur, mid-tibia may have an indistinct light ring, otherwise as hind tibia: light brown darkened distally, tarsi light brown. Wing light brown, halteres yellow. Abdominal TI white/bright yellow. TII highly variable among both the paratypes and MD specimens, ranging from yellow to black, often yellow-white with a brown band covering roughly the middle third of TII. The incisures between TIITIII and TIII-TIV narrowly light; TIII brown; TIV light on posterior $70-75 \%$ length of tergite, anterior brown; TV anterior 30- 40\% white with posterior brown. TVI, TVII, TVIII brown with incisures slightly lighter. Hypopygium white. Holotype and most of the slide-mounted paratypes are mounted intact in lateral view, largely obscuring details of the genitalia. Based on three paratypes, the inferior volsella is broad basally, apically bluntly rounded and bending posterior. In two specimens a small triangular spur is present at base of inferior volsella. In MD specimens, the inferior volsella tapers gradually from a broad base to a more conical rounded tip, also bending posterior (Figs 11B, $11 \mathrm{C}, 12)$. Gonostylus with strong crista dorsalis.

Female: (based on allotype, paratypes and MD specimens): Antennae with preapical bristle; terminal flagellomere slightly longer than the 3 preceding flagellomeres (i.e., $\mathrm{AR}=1.12, \mathrm{n}=4$ ). Thorax brown to dark brown, humeri lighter; vittae, notum darker brown. Scutellum brown with 1 row of fine bristles. Femurs apically brown to black, lighter at base. Fore-tibia brown with me- dian white ring covering half of segment; fore-tarsi brown; LR $=0.58$ (Boesel 1983), LR =0.57 (MD). Mid and hind legs with light tibiae slightly darker distally mid tibia may bear an indistinct light ring; tarsi light brown. Typically, TI, TV and TVI are light yellow/white but may be brownish in dark specimens. Tergite 5 is most consistently light, although it may be brownish in dark specimens (Fig. 10B). Sternites yellow, SIV-SVIII with medial spine patches. Spermathecae oval with ducts posterior; ducts with anterior " $\mathrm{S}$ " bend otherwise straight.

Specimens examined: Peabody Museum of Yale University, M. Boesel collection: holotype $\hat{\sigma}+$ paratype $\hat{\sigma}$, allotype $q$ and 3 additional $\hat{\sigma}$ paratypes Put in Bay, Ohio, USA, 21 June 1946; paratype $q$ Oxford, Ohio, USA, 4 June 1978, $\widehat{\jmath}$ paratype - hypopygium mounted separately, Put in Bay, Ohio, USA, 30 June 1924; pinned paratypes $68 \delta \widehat{\delta}$ and $37 q q$ dates span 1925-1976, locations include $\mathrm{OH}$, Michigan, New York, Delaware and Pelee Is. Canada (details in Boesel 1983).

Canadian National Collection of Insects, Ottawa: DRO 32.4-50 1 ठ + pex Green Creek Ontario 19 June 1967; Towson University Entomology Museum (Barcode Specimen IDs): SEG46 9 , SEG47우,

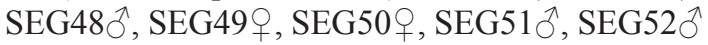
Baismans Run, Oregon Ridge Park, Baltimore, USA, 11. Sept. 2010; CHIM830 3 pex Chimney Branch, 1 July 2002.

Keys to distinguish $C$. diversus and $C$. festivellus from morphologically similar species

\section{Larvae, numbering adapted from Epler (2001)}

16. Mentum with median tooth very wide: 4-6 times as wide as 1 st lateral................ flavocinctus

16'. Mentum with median tooth less wide, 2.8-3.5 times as wide as 1 st lateral.

16A. Mentum with median tooth projecting strongly forward having a bluntly pointed apex and somewhat angular sides (Fig. 5A) ............... 16B

$16 A^{\prime}$. Mentum with median tooth not projecting far forward, apex more broadly rounded(dome-shaped) (Fig. 5B) .. 17

16B. AR 1.3-1.6; galea of maxilla with no more than 2 rows of pectinate lamellae; medium-size claws on anterior parapods with terminal tooth only slightly longer that the next inner tooth; claw - index $* 1.6$. C. diversus

16B' AR 2.0-2.5 galea of maxilla with 3-4 rows of pectinate lamellae; medium-size claws on anterior parapods with terminal tooth much 
longer that the next inner tooth; claw - index 3.7 . C. cylindraceus

17. Setal tufts on abdominal segments either absent or reduced, $<50 \mu \mathrm{m}$ C. politus

17 '. Setal tufts more developed, about $80-240 \mu \mathrm{m}$ in length.

18. L4 hairs at least half the length of the segment; VM plate reaching first lateral tooth. C. festivellus

$18^{\prime}$. L4 hairs about $1 / 4$ th to $1 / 3$ rd of the length of the segment 19

19. Galea of maxilla with numerous pectinate lamellae set in 2 or more rows; medium-sized claws of anterior parapods with terminal tooth distinctly longer (ca. twice) than the next inner tooth; basal antennal segment L/W about 3; claw-index 1.9-2.0 C. albiforceps
19'. Galea of maxilla with pectinate lamellae absent or a few set in a single row; medium-size claws on anterior parapods with terminal tooth only slightly longer that the next inner tooth; basal antennal segment $\mathrm{L} / \mathrm{W}$ about 2 ; claw-index $1.4 \ldots .$. C. vierriensis

*Claw-index $=$ ratio length terminal tooth and penultimate tooth of the medium sized claws of the anterior parapods (Fig. 6).

\section{Pupae, numbering adapted from Simpson et al. (1983)}

9. Pedes spurii B well developed on abdominal segments II and III .... C. cylindraceus gr.

9'. Pedes spurii B well developed only on abdominal segment II, weakly on III (C. festivellus gr.) 13

13. Thoracic horn present
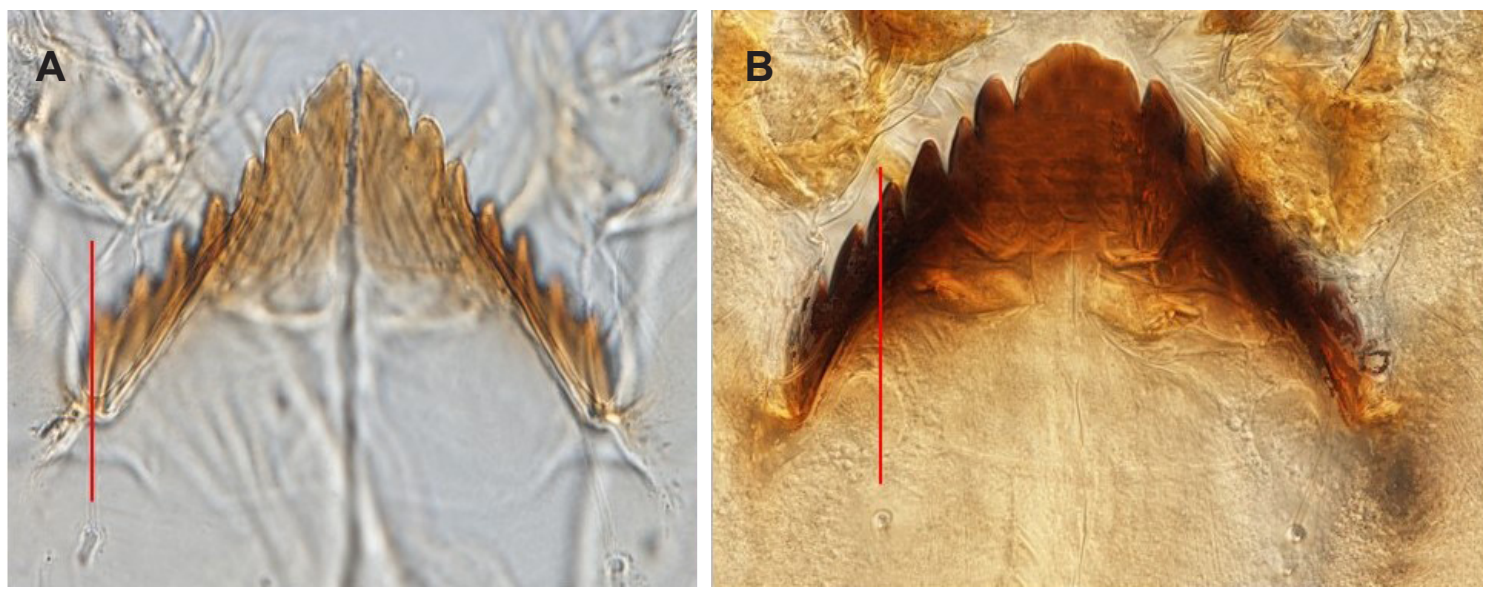

Figure 5. A) Cricotopus diversus; mentum with SSm-setae. Oregon Ridge Park, Baismans Run, 11 September 2010. B) Cricotopus festivellus; mentum with SSm-setae, position relative to lateral teeth indicated by red vertical line. Veluwerandmeer, 5 October 2016.
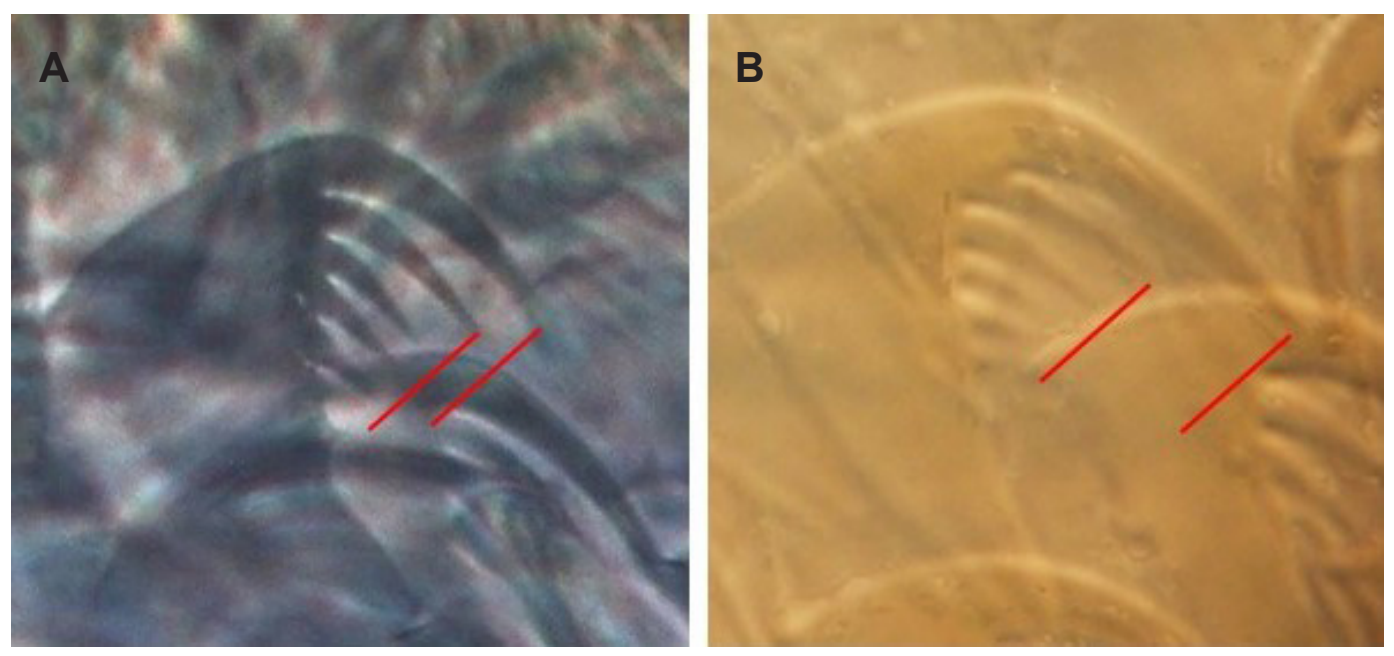

Figure 6. A) Middle sized claws of anterior parapods of Cricotopus diversus. Oregon Ridge Park, Baismans Run, 11 September 2010. B) Middle claws of anterior parapods of Cricotopus festivellus. Veluwerandmeer, 5 October 2016. 

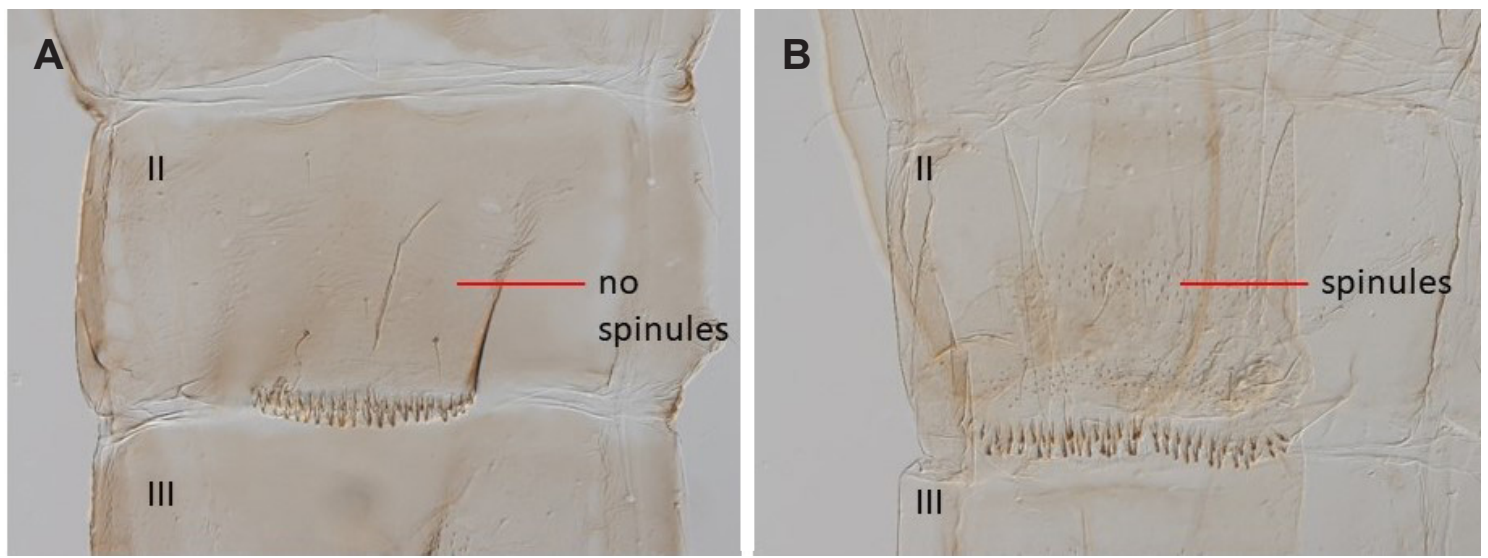

Figure 7. A) Cricotopus diversus pupal exuviae segment 2. Oregon Ridge Park, Baismans Run, 11 September 2010. B) Cricotopus festivellus exuviae segment 2. Sprangcapelle Waalwijk, 4 August 1992.
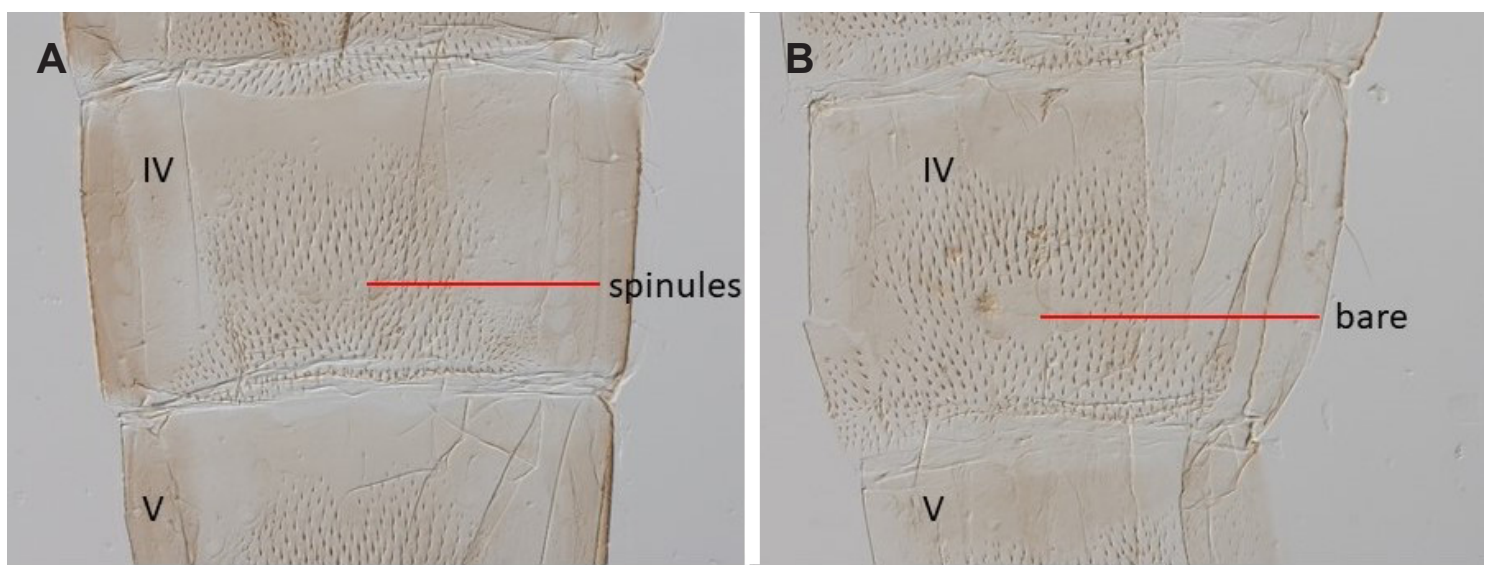

Figure 8. A) Cricotopus diversus exuviae segment 4. Oregon Ridge Park, Baismans Run, 11 September 2010. B) Cricotopus festivellus exuviae segment 4. Sprangcapelle Waalwijk, 4 August 1992.

13'. Thoracic horn absent

C. flavocinctus

14. Shagreen on TIV distinctly separated into anterior and posterior fields (i.e., point bands)

C. albiforceps

14'. Shagreen on TIV not separated into separate fields ...... .. 15

15. TII with extensive spinule patches or at least a transverse row of spinules (Fig. 7B); TIV median and posterior spinule bands joined laterally, leaving a conspicuous median bare spot in shagreen field (Fig. 8B) C. festivellus

15'. TII bare, or with a few isolated spinules anterior to hooklet row (Fig. 7A); TIV median and posterior spinule fields more broadly joined, with or without a small oval median bare spot (Fig. 8A).... C. diversus

\section{Adult males}

1. TIV with yellow-white band covering posterior $65-75 \%$ of tergite; TV with yellow-white band on anterior $30-40 \%$ of tergite (Fig. 9); inferior volsella of gonocoxite broad basally, tapering, bluntly rounded apically and bending posteriomedially... C. diversus

1'. TIV with yellow-white band covering posterior $30-40 \%$ tergite; TV with white or light brown band on anterior $20-30 \%$ of tergite (Fig. 10A) inferior volsella of gonocoxite medially broadened (truncated) with apex directed posteriorly $C$. festivellus

\section{Discussion}

Genetic evidence supports $C$. diversus as a species separate from C. festivellus. Comparison of COI5P sequence data from $11 C$. festivellus collected in Norway and Sweden with that of the BIN containing the 7 specimens of $C$. diversus and 7 specimens from Canada showed a mean within-group distance of $0.2 \%$ for $C$. festivellus and $1.1 \%$ for the Nearctic $C$. diversus group. In contrast, the mean between-species distance was $13 \%$.

Cricotopus diversus larvae were reared and the associated adult males and females have been compared with Boesel's (1983) description and the $C$. diversus type series. Adult male $C$. diversus are distinguished from other Cricotopus species 

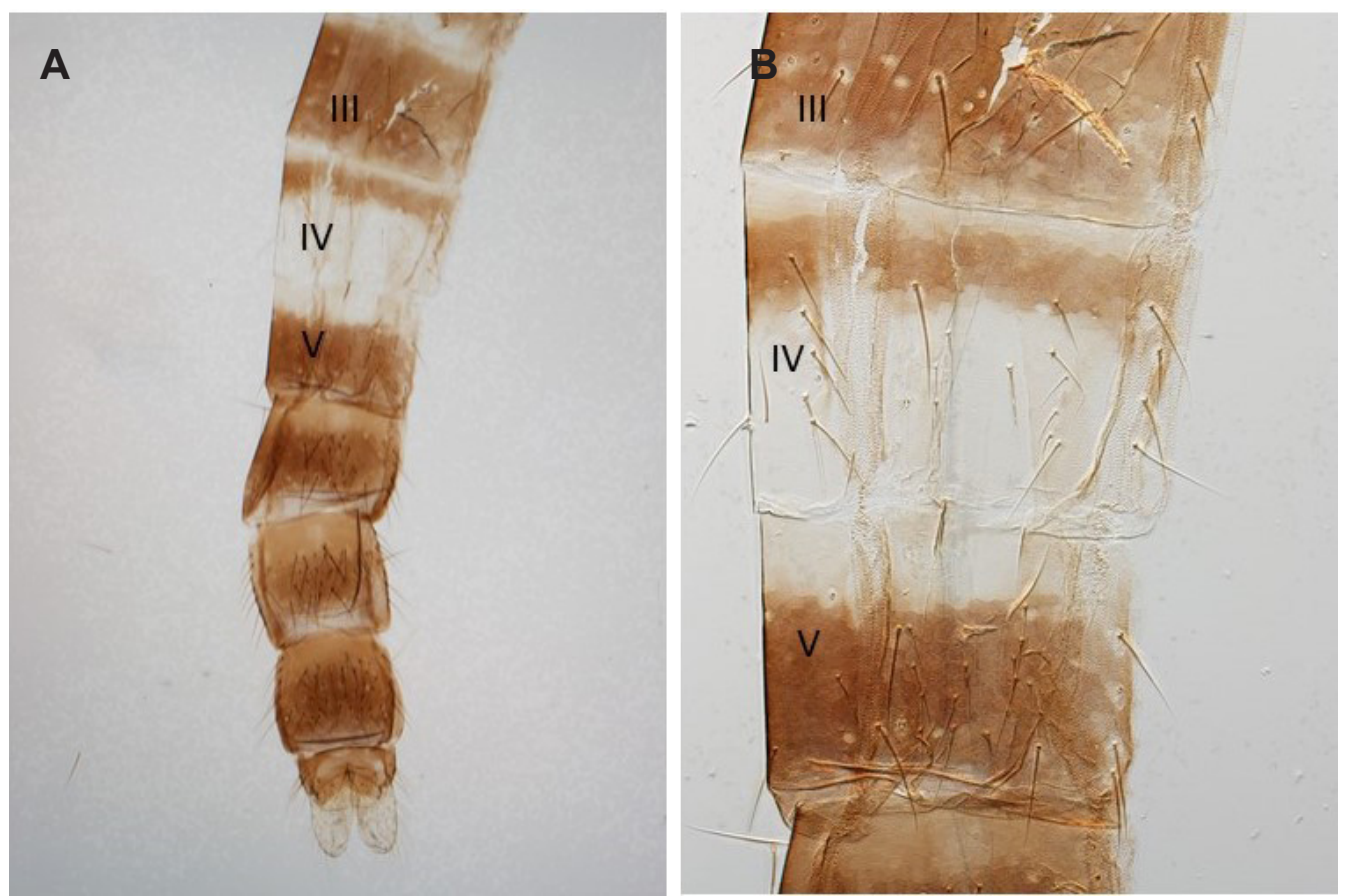

Figure 9. A) Cricotopus diversus male abdominal segments 3-8. Oregon Ridge Park, Baismans Run, 11 September 2010. B) Cricotopus diversus male, detail segment 4 and 5 (same specimen as in Fig. 9A).
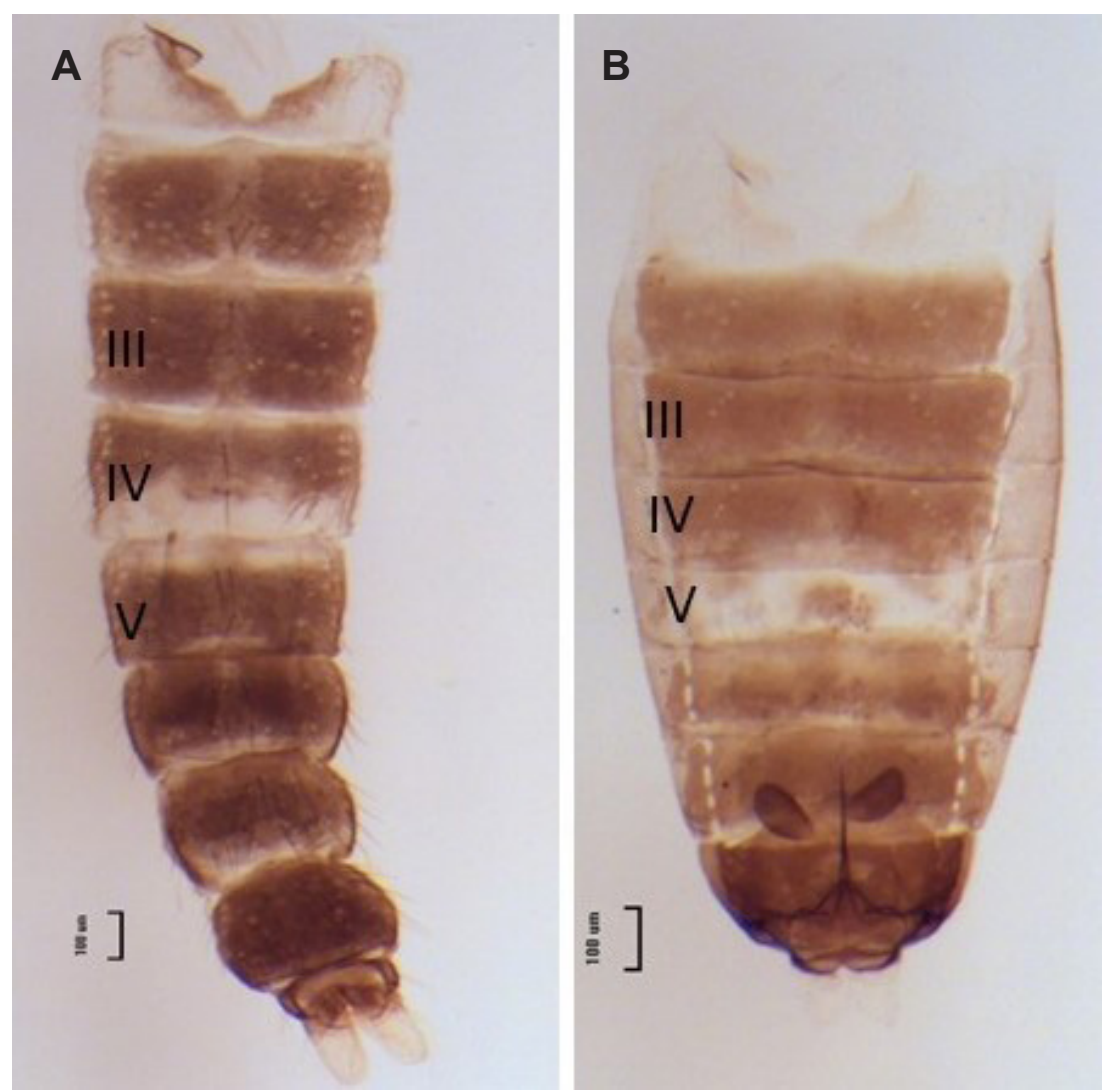

Figure 10. A) Cricotopus festivellus male. Målsjøen, Klæbu, 30 May 2011. B) Cricotopus festivellus female. Blomstertjønna, Bymarka, Trondheim, 31 July 2011. 

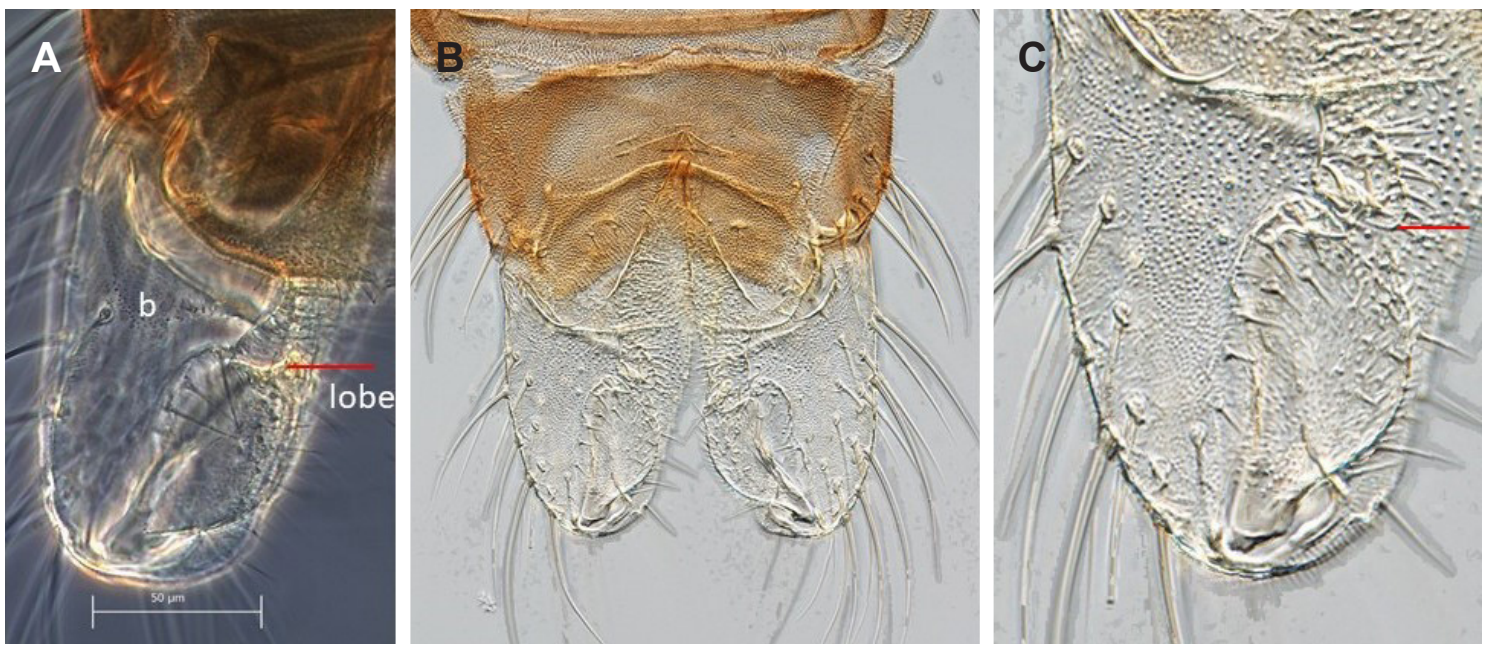

Figure 11. A) Cricotopus festivellus hypopygium. "b": gonocoxite; pond, Ringve Botanical Garden, Trondheim, 24 July 2011. B) Cricotopus diversus male hypopygium; Oregon Ridge Park, Baismans Run, 11 September 2010. C) Cricotopus diversus male hypopygium; arrow: inferior volsella of gonocoxite. Same specimen as in B.

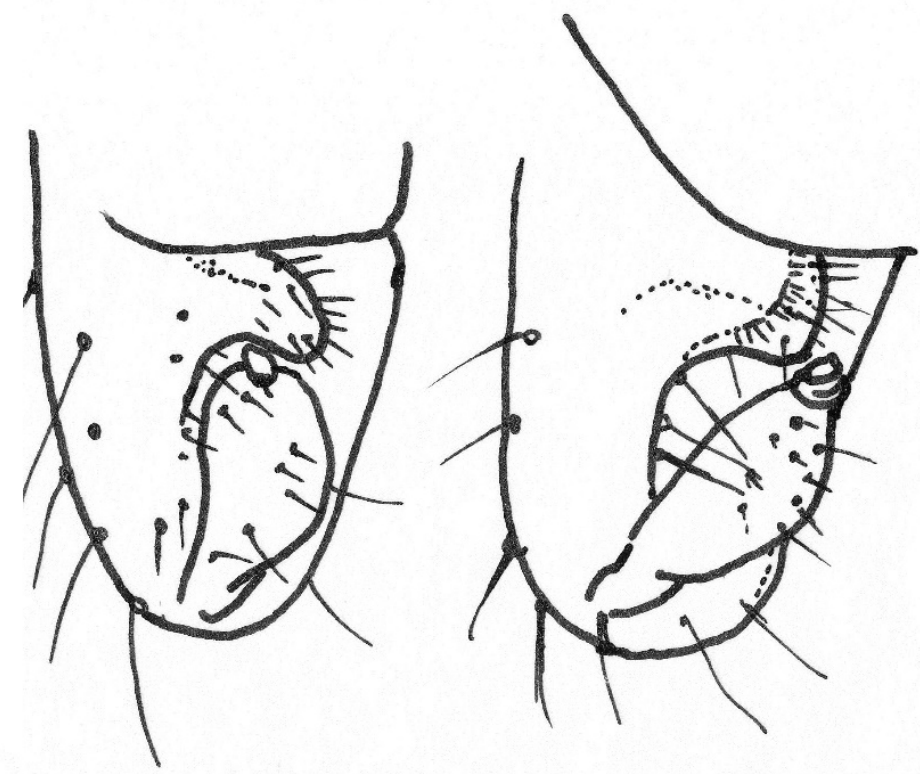

Figure 12. Comparison of inferior volsellae of C. diversus (left) and C. festivellus (right). Same individuals as Fig. 11.

of eastern North America by the blackish-brown (fuscous) abdomen, except for tergites 1, 4 and 5 . Tergite 1 is completely yellow-white, whereas the posterior $2 / 3$ to $3 / 4$ of tergite 4 is white, with only the anterior $1 / 4$ of tergite 5 white. Tergite 2 is variably darkened, and the incisures between tergites 2 and 3 may bear narrow light bands. Examination of the type series, both slide-mounted and pinned, show this pattern of pigmentation to be very consistent.

The pattern of pigmentation on tergites 4 and 5 of the adult male distinguishes $C$. diversus from C. festivellus and other members of the festivellus species group (Hirvenoja 1973). In C. festivellus, only the posterior $1 / 4$ of tergite 4 and the anterior $1 / 4$ of tergite 5 are white (Fig. 10); in contrast, tergite 4 of $C$. diversus is largely white with only the anterior $1 / 4$ to $1 / 3$ darkened (Fig. 9). Both species have tergite 1 completely white. In addition, the male hypopygium differs in the form of the inferior volsellae, which in C. festivellus bend posteriorly, but have a more angular, flattened apex than C. diversus (Figs 11-12). In C. festivellus the base of the inferior volsellae may bear a slight bifurcation (Hirvenoja 1973) which was observed in two C. diversus paratypes. 
Identification of adult Cricotopus species also relies on the male hypopygium, especially the inferior volsella. Boesel (1983) noted that the angle of view affected the shape of the inferior volsella, and thus his Fig. 8 is ambiguous: the diagram on the left resembles that of $C$. festivellus whereas that on the right matches our $C$. diversus. The holotype and most of the paratypes were slide-mounted intact in lateral view, thus the inferior volsella was either obscured or difficult to examine. However, the hypopygium of one paratype had been dissected and mounted dorsally: this is represented in Fig. 8, diagram on the right (Boesel 1983) and it matches that of our specimens. We conclude that the inferior volsella of $C$. diversus is simple, the broad base tapering to a rounded apex which bends posterio-medially. The base of the inferior volsella is both broad and thick, becoming thinner at the tip, which sometimes is slightly bent out of the plane of focus, thus making the inferior volsella appear slightly angular, but not to be confused with C. festivellus.

Female $C$. diversus differ in coloration from males: tergites 1,5 and 6 may be totally white, although T1 and TVI may be somewhat darkened. The antenna bears an apical bristle. Spermathecae are ovoid with S-curved ducts. Female $C$. diversus appear similar to female $C$. festivellus as figured in Hirvenoja (1973) with tergites 5 and 6 white. We have not found features that consistently distinguish female $C$. diversus from $C$. festivellus.

We found that larval $C$. diversus are most easily distinguished from $C$. festivellus, by the lateral placement of the submental setae: they are placed in line with the outside of the sixth mental tooth in $C$. diversus, whereas they are placed more medially, in line with the fourth or fifth mental tooth in C. festivellus (Fig. 5). All other members of the festivellus species group have 3 or 4 rows of pectinate lamellae on the galea of the maxilla (Hirvenoja 1973), whereas $C$. diversus has at most two rows of pectinate lamellae.

Cricotopus festivellus can be separated from other (Palearctic) species in the festivellus species group, as follows: C. flavocinctus has a broader central mental tooth; the median-sized claws of the anterior parapods have a longer subterminal tooth in C. cylindraceus. Cricotopus festivellus can be distinguished from $C$. albiforceps and $C$. vierriensis by having longer L4 setal tufts (Cuppen and Tempelman 2018).

Did LeSage and Harrison (1980) actually find $C$. diversus? We examined the single pupal-adult male association of $C$. "festivellus" (from Green
River, Ontario Canada) produced from their study, and confirmed their description of the exuviae. Key features match our description of $C$. $d i$ versus: frontal setae on prefrons, $\sim 40 \mu \mathrm{m}$ long; pointed thoracic horn covered with spinules, dimensions $184 \times 16 \mu \mathrm{m}$. Weakly granular along the dorsal eclosion line, pedes spurii B on abdominal segment 2 , but weak on segment 3 . The distribution of lateral abdominal setae matches that of $C$. diversus: $1 \mathrm{~L}$-seta on segment 1, $3 \mathrm{~L}$-setae on segments $2-7$, and 4 L-setae on segment 8 . The anterior and posterior spinule patches on tergites III-IV are weakly joined laterally, leaving an oval median bare patch which could be either $C$. festivellus or C. diversus. However, tergite II was bare except for a very narrow band of minute spinules just anterior to the hooklet row, which identifies $C$. diversus. Pigmentation of the associated adult male is consistent with $C$. diversus: T1 light, the anterior $40 \%$ of TII light, narrow light incisures TII-TIII and TIII-TIV, posterior $70 \%$ of TIV and the anterior $35 \%$ of TV are light. The inferior volsella was very clearly flattened-conical, tapering and curving postero-medially. Based on this specimen as well as the descriptions in their paper, we conclude that LeSage and Harrison (1980) actually found $C$. diversus in Southern Ontario streams.

Information provided by the BIN system in BOLD shed more light on the degree of relatedness and geographic distribution of these species. Barcode data for Cricotopus specimens in BIN AAP5924, which includes $C$. diversus and other specimens collected in Ontario, Canada (Centre for Biodiversity Genomics) show a within-BIN genetic distance of $1.1 \%$ suggesting these are the same species. Specimen records in BIN AAV1707, all identified as $C$. festivellus from Norway and Sweden, had a within-BIN genetic distance of only $0.2 \%$, versus a $13 \%$ distance with the Nearctic "diversus" BIN. Nearctic C. diversus have clearly differentiated from west Palaearctic C. festivellus.

\section{Ecological notes}

Cricotopus festivellus is widely distributed and rather common in Western Europe (Moller Pillot, personal communication; Murray et al. 2018). It inhabits slowly flowing and standing waters with clean water such as lakes (Fig. 1B), large pools in the coastal dune area, ditches in regions with peaty soils and poorly buffered moorland pools.

Cricotopus diversus larvae were found in a small forest stream, in a reach where the forest canopy had been removed for a gas pipeline (Fig. 1A) and the increased light supported visible algal growth (primarily diatoms with some filamentous green 
algae) and higher diversity of chironomids than in the adjacent forested reaches of the stream. Although down-cutting of the stream channel and fine sediment deposition was obvious, the water quality of Baismans Run was very good: Gresens and Ferrington (2010) studied chironomid emergence at a site $350 \mathrm{~m}$ downstream and measured an average of $8.4 \mu \mathrm{g} / \mathrm{L}$ total phosphorus, $2.1 \mathrm{mg} / \mathrm{L}$ nitrate and $144 \mu \mathrm{S}$ conductivity. A total of 75 chironomid species was observed at this downstream forested reach, based on an 8-month survey of chironomid pupal exuviae (Gresens and Ferrington 2010). Pupal exuviae were also collected from Chimney Branch, another small forested stream (Table 1) with good water quality: $13 \mu \mathrm{g} / \mathrm{L}$ total phosphorus, $1.2 \mathrm{mg} / \mathrm{L}$ nitrate and $290 \mu \mathrm{S} / \mathrm{cm}$ conductivity.

LeSage and Harrison (1980b) presented a detailed ecological study of 15 Cricotopus species in Salem Creek, Ontario. The stream was enriched by runoff from pasture and row crops, but remained welloxygenated, with stable cobble-gravel substrate encrusted with marl that supported seasonally abundant algae (diatoms and Cladophora). Here, the preferred microhabitat of $C$. "festivellus" was in a pool with a hard substrate and a thin layer of detritus; the species was absent from nearby rivers impacted by urban and industrial pollution (LeSage and Harrison 1980b). In the Mid Atlantic US, $C$. diversus was found in small woodland streams of good water quality. Canadian BIN records on BOLD point to collections from both lakes and riffle areas of rivers in forested areas and parks. Mating swarms of $C$. diversus were observed in western Lake Erie in first half of the $20^{\text {th }}$ century (Boesel 1983). More recently, Failla et al. (2015) found larvae of $C$. bicinctus (pollution tolerant) and larvae of an unidentified Cricotopus sp. in the same region, perhaps reflecting the decline in water quality of Lake Erie. It appears that $C$. diversus prefers lower water velocity and is restricted to situations of moderately good water quality.

\section{Illustrations}

Fig. 1, 4, 6A, 10, 11A and 12: S. Gresens; Fig. 2, 3, 5, 6B, 7-9,11B-C: H. Cuppen and D. Tempelman.

\section{Acknowledgements}

The NTNU University Museum funded the DNA barcoding of $C$. diversus specimens and related laboratory work. SEG received fellowships from Towson University and the American Scandinavian Foundation in support of her sabbatical at NTNU. Rijkswaterstaat (Lelystad, The Netherlands) granted us permission to use photography equipment at the Lelystad laboratory. Rink Wiggers (Groningen) provided material of $C$. festivel- lus from one location in the Netherlands. The manuscript benefitted from comments by Bohdan Bilyi, who also revised the keys to larvae, and from an anonymous reviewer. We thank The Canadian National Collection of Insects for the loan of the "festivellus" slide. The Peabody Museum of Yale University graciously arranged for SEG to examine the $C$. diversus types, and Erik Lazo-Wasem provided high-resolution images of the holotype and key paratypes.

\section{References}

Ashe, P. and O'Connor J.P. 2012. A World Catalog of Chironomidae (Diptera) Part 2. Orthocladiinae (Section A). The Irish Biogeographical Society, Dublin, 968 p.

Boesel, M.W. 1983. A review of the Genus Cricotopus in Ohio, with a key to adults of species of the Northeastern United States (Diptera, Chironomidae). - Ohio Journal of Science 83:74-90.

Cuppen, H. and Tempelman, D. 2018. Identification key for the 4th stage larvae of northwest European species of Cricotopus (Diptera: Chironomidae: Orthocladiinae). - Lauterbornia 85:69-90.

Ekrem, T., E. Willassen, E. and Stur, E. 2007. A comprehensive DNA sequence library is essential for identification with DNA barcodes. - Molecular Phylogenetics and Evolution 43:530-542. DOI: http://doi.org/10.1016/j.ympev.2006.11.021

Epler, J.H. 2001. Identification Manual for the Larval Chironomidae (Diptera) of North and South Carolina. Special Publication SJ2001SP13. North Carolina Department of Environmental and Natural Resources Division of Water Quality.

Failla, A.J., Vasquez, A.A., Hudson, P., Fujimoto, M., and Ram, J.L. 2015. Morphological identification and COI barcodes of adult flies help determine species identities of chironomid larvae (Diptera, Chironomidae). - Bulletin of Entomological Research 106:34-46. DOI: https:// doi.org/10.1017/S0007485315000486

Gresens, S.E. and Ferrington, L.C., Jr. 2010. Chironomid species assemblages of streams draining areas of serpentine versus non-serpentine bedrock, pp 55-69. In: Ferrington, L.C., Jr. Proceedings of the $X V$ International Symposium on Chironomidae. Chironomid Research Group, University of Minnesota, Saint Paul, MN, 385 p. 
Gresens, S.E., Stur, E. and Ekrem, T. 2012. Phenotypic and genetic variation within the Cricotopus sylvestris species-group (Diptera, Chironomidae), across a Nearctic - Palaearctic gradient. - Fauna Norvegica 31:137-149. DOI: https://doi.org/10.5324/fn.v31i0.1417

Haase, R. and Nolte U. 2008. The invertebrate species index (ISI) for streams in southeast Queensland, Australia. - Ecological Indicators 8:599-613. DOI: https://doi.org/10.1016/j.ecolind.2007.08.005

Hirvenoja, M. 1973. Revision der Gattung Cricotopus van der Wulp und ihrer Verwandten (Diptera: Chironomidae). - Annales Zoologica Fennica 10: 1-363.

Krosch, M.N., Cranston, P.S., Baker A.M. and Vink, S. 2015. Molecular data extend Australian Cricotopus midge (Chironomidae) species diversity, and provide a phylogenetic hypothesis for biogeography and freshwater monitoring. - Zoological Journal of the Linnean Society 175:496-509. DOI: https://doi.org/10.1111/ zoj. 12284

Kumar, S., Stecher, G. and Tamura, K. 2016. MEGA7: Molecular Evolutionary Genetics Analysis version 7.0 for bigger datasets. - Molecular Biology and Evolution 33:1812-1819. DOI: https://doi.org/10.1093/molbev/msw054

Langton, P.H., 1991. A key to pupal exuviae of West Palaearctic Chironomidae. Huntingdon (private publ.). $386 \mathrm{p}$.

LeSage, L. and Harrison, A.D. 1980a. Taxonomy of Cricotopus Species (Diptera: Chironomidae) from Salem Creek, Ontario. - Proceedings of the Entomological Society of Ontario 111: 57-114.

LeSage, L. and Harrison, A.D. 1980b. The biology of Cricotopus (Chironomidae: Orthocladiinae) in an algal-enriched stream: Part 1. Normal biology. - Archiv für Hydrobiologie/ Supplement 57:375-418.

Moller Pillot, H.K.M. 2013. Chironomidae Larvae. Biology and Ecology of the aquatic Orthocladiinae. KNNV Publishing, Zeist, The Netherlands, $312 \mathrm{p}$.

Murray, D.A., O’Connor, J.P. and Ashe, P.J. 2018. Chironomidae (Diptera) of Ireland - A review, checklist and their distribution in Europe. Occasional Publication of the Irish Biogeographical Society, Dublin, 404 p.

Oliver, D.R, 1977. Bicinctus-Group of the genus Cricotopus van der Wulp (Diptera: Chironomidae) in the Nearctic with description of a new species. - Journal of the Fisheries Research Board of Canada 34:1-104.

Ratnasingham, S. and Hebert, P.D.N. 2007. BOLD: The barcode of life data system (www.barcodinglife.org). - Molecular Ecology Notes 7:355364. DOI: https://doi.org/10.1111/j.14718286.2007.01678.x

Ratnasingham, S. and Hebert, P.D.N. 2013. A DNA-based registry for all animal species: the Barcode Index Number (BIN) System. - PLOS ONE 8(8):e66213. DOI: https://doi. org/10.1371/journal.pone.0066213

Sæther, O.A. 1980. Glossary of chironomid morphological terminology (Diptera: Chironomidae). - Entomologica Scandinavica Supplement 14:1-51. Lund, Sweden.

Sublette, J.E. 1964. Chironomidae (Diptera) of Louisiana I. Systematics and immature stages of some lentic chironomids of West-Central Louisiana. - Tulane Studies in Zoology 11:109150 . 